\title{
High-Level Nuclear Wastes and the Environment: Analyses of Challenges and Engineering Strategies
}

\author{
Mukhtar Ahmed Rana \\ Physics Division, Directorate of Science, PINSTECH, Islamabad, Pakistan \\ Email: marana@pinstech.org.pk,rana@alumni.nus.edu.sg \\ Received February 11, 2012; revised April 2, 2012; accepted April 19, 2012
}

\begin{abstract}
The main objective of this paper is to analyze the current status of high-level nuclear waste disposal along with presentation of practical perspectives about the environmental issues involved. Present disposal designs and concepts are analyzed on a scientific basis and modifications to existing designs are proposed from the perspective of environmental safety. A new concept of a chemical heat sink is introduced for the removal of heat emitted due to radioactive decay in the spent nuclear fuel or high-level radioactive waste, and thermal spikes produced by radiation in containment materials. Mainly, $\mathrm{UO}_{2}$ and metallic $\mathrm{U}$ are used as fuels in nuclear reactors. Spent nuclear fuel contains fission products and transuranium elements which would remain radioactive for $10^{4}$ to $10^{8}$ years. Essential concepts and engineering strategies for spent nuclear fuel disposal are described. Conceptual designs are described and discussed considering the long-term radiation and thermal activity of spent nuclear fuel. Notions of physical and chemical barriers to contain nuclear waste are highlighted. A timeframe for nuclear waste disposal is proposed and time-line nuclear waste disposal plan or policy is described and discussed.
\end{abstract}

Keywords: High-Level Nuclear Waste; Nuclear Waste Containment and Disposal; Environment; Conceptual Model Designs; Radioactivity Damage; Chemical Heat Sink

\section{Introduction}

The issue of disposal of high-level radioactive nuclear waste, e.g., spent nuclear fuel (SNF), is not new and needs urgent attention due to its increasing volume worldwide. It is now one of the most important but controversial problems of nuclear technology. Only safe and successful solutions to this problem would guarantee the long-term future of nuclear power. It is extremely difficult for policy-makers worldwide to develop a consensus on final disposal of high-level nuclear waste. The disposal of high-level nuclear waste [1-3] is gaining a new momentum [4] due to the need for more electricity with minimal emission of $\mathrm{CO}_{2}$ and other greenhouse gases to limit global warming.

Apart from disposal of safely produced SNF or highlevel radioactive waste, the possibility of nuclear reactor accidents [5-8] also requires deep understanding of this issue from the perspective of failure. Forward planning [9] is the only solution of this extremely sensitive issue. The following three-pronged criterion can potentially play a significant role in achieving safety assurance on this important and near- and far-future humanity related issue. First, nuclear test [10] and accident sites can be helpful in forward planning $[11,12]$. Second important point which can be helpful in finding out the safe solution of this issue, is sharing of knowledge from various nuclear workplaces worldwide [13-17]. Strict critical review of policies, principles and implementation procedure for high-level radioactive waste disposal should be mandatory.

Safety of the nuclear waste containment and disposal can be assured by making the effective use of science in policy making. A policy is a set of guiding principles for making procedures of implementation of a scheme. A public policy is quite different in nature from a private policy and is complex subject. It requires the optimization of a number of technical as well as well as social parameters. Policy for the high level nuclear wastes (HLW) disposal is a multifaceted issue and it requires to resolve a number of inter-related problems. In situations like disposal of HLW, comprehensive evaluation of policy success is extremely important as implications of a failure can be smashingly serious for the present and future life at earth. Risk informed changes to the technical requirements of a HLW disposal policy is a natural solution, but stringent complications in assessment of the risks involved due to unpredictability of future geophysical events over a long time scale of more than 100,000 years are the major worries. 
Main objective of this paper is to present/analyze the current status of high-level nuclear waste and/or spent nuclear fuel disposal along with practical scientific thoughts about the issue. Present disposal designs and concepts are analyzed on scientific bases and modifications to the existing designs are proposed. Next section describes an assessment of the nuclear waste disposal problem and its implementation plan. Section 4 presents analysis of current nuclear waste disposal procedures and a brief summary of a method for monitoring the radiation damage in nuclear waste containers. Section 5 is composed of status comments on different aspects of nuclear waste disposal along with a modified burial design. Paper ends with conclusions of the investigation.

\section{Climate Change and Nuclear Energy}

One of the biggest questions of the time is how to meet the challenges caused by escalating climate change and growing energy demand around the globe. Nuclear energy can play a central role in mitigating the global climate change by minimizing the emission of $\mathrm{CO}_{2}$ and other greenhouse gases in commercial energy supply [18]. Public acceptance to nuclear energy is very low due to Chernobyl [9,11,19] and Three Mile Island [20] accidents. It is being realized that factual public awareness of nuclear energy and related issues, especially security and environmental safety of nuclear engineering designs needs to be raised. Table 1 shows a foresight of energy consumption scenarios in 2050 keeping fossil-fuel carbon emissions same as at present to keep a hold on the climate change [21]. If the level of nuclear energy expected in the above mentioned scenario is considered, thoughtful and coherent research efforts around a few central themes would be needed. Nuclear reactor safety and solution to the problems associated with spent nuclear fuel

Table 1. Energy consumption scenario (Sailor et al. 2000).

\begin{tabular}{lcccc}
\hline & 1997 & 1997 & 1997 & 2050 \\
& World & USA & France & \\
\hline Population (millions) & 5857 & 268 & 59 & 9000 \\
Total primary energy (EJ/year) & 400 & 99 & 10.3 & 900 \\
Fossil fuel (EJ/year) & 343 & 85 & 6.2 & 300 \\
Renewable (EJ/year) & 30 & 5.2 & 0.7 & 300 \\
Nuclear (EJ/year) & 25 & 7.1 & 4.1 & 300 \\
Total per capita (EJ/year) & 68 & 371 & 175 & 100 \\
Fossil fuel fraction (\%) & 86 & 85 & 61 & 33 \\
Nuclear energy & & & & \\
Generation (GW-year/year) & 259 & 72 & 43 & 3300 \\
Per capita (kW-year/year) & 0.04 & 0.27 & 0.73 & 0.36 \\
Fraction of electricity (\%) & 17 & 18 & 79 & $>50$ \\
CO ${ }_{2}$ emission (MTC) & 6232 & 1489 & 102 & 5500 \\
\hline
\end{tabular}

(SNF) or HLW are major concerns.

Apart from Chernobyl and Three Mile Island, safety record of nuclear reactors has been extremely good. More than 8500 nuclear reactors built outside former Soviet Union, there has been no major radioactivity release accident. There have been considerable improvements in reactor designs after above mentioned nuclear accidents [21]. Continued commitment to the best science for improvements in safety aspects of nuclear technology, keeping the economic build low, is essentially needed. Upcoming nuclear reactors will have considerably better safety perspective compared with present. The possibility of core damage in Advanced Boiling Water Reactor (ABWR), a US design, is estimated to be $2 \times$ $10^{-7}$ per reactor per year [22] SNF or HLW is a complicated issue. Some of nuclear countries deem SNF as a disposable waste while others as an asset which associates a kind of paradox with it. Problems associated with this paradox issue and possible solutions are discussed in the next section.

\section{Problem Assessment and Implementation Plan}

\subsection{Composition of SNF, A Representative Radioactive Waste}

Although composition of SNF is reactor, fuel and burn-up specific, a general dependence of its composition on storage time is described in this section. Spent nuclear fuel shows almost a complete spectrum of radioactivity. Some of elements in SNF will remain radioactive for hours to a few years whereas others for thousands to millions of years. Rate of change of any of radioactive nuclei in SNF can be represented by the following equation,

$$
\frac{\mathrm{d} N_{i}}{\mathrm{~d} t}=\left.\frac{\mathrm{d} N_{i}}{\mathrm{~d} t}\right|_{\text {form }}-\left.\frac{\mathrm{d} N_{i}}{\mathrm{~d} t}\right|_{\text {decay }}
$$

whereas concentration or number of a specific specie of nuclei at any time are given by the following equation,

$$
N_{i}(t)=N_{i}\left(t_{o}\right)+\left.\int_{t_{o}}^{t} \frac{\mathrm{d} N_{i}}{\mathrm{~d} t}\right|_{\text {form }}-\left.\int_{t_{o}}^{t} \frac{\mathrm{d} N_{i}}{\mathrm{~d} t}\right|_{\text {decay }}
$$

where $t_{o}$ is the starting time whereas $t$ is any time afterwards. It is clear from above equations that composition of SNF will continue changing, but in a quite deterministic way assuming initial composition of SNF is known. It is an important point to be considered while selecting containment materials and disposal site.

\subsection{High-Level Nuclear Waste Disposal Implementation Plan or Policy}

The conceptual model of a reliable scientific investigation is shown in Figure 1(a). Analysis and execution of 


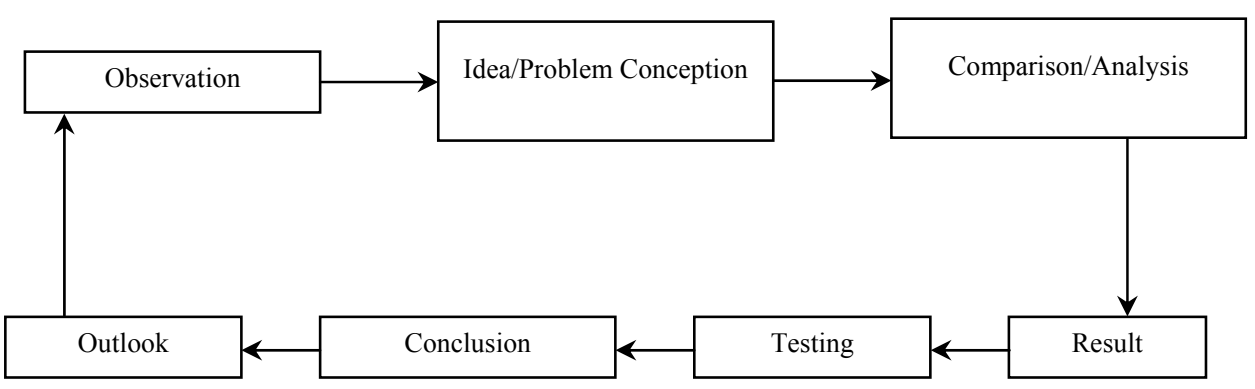

(a)

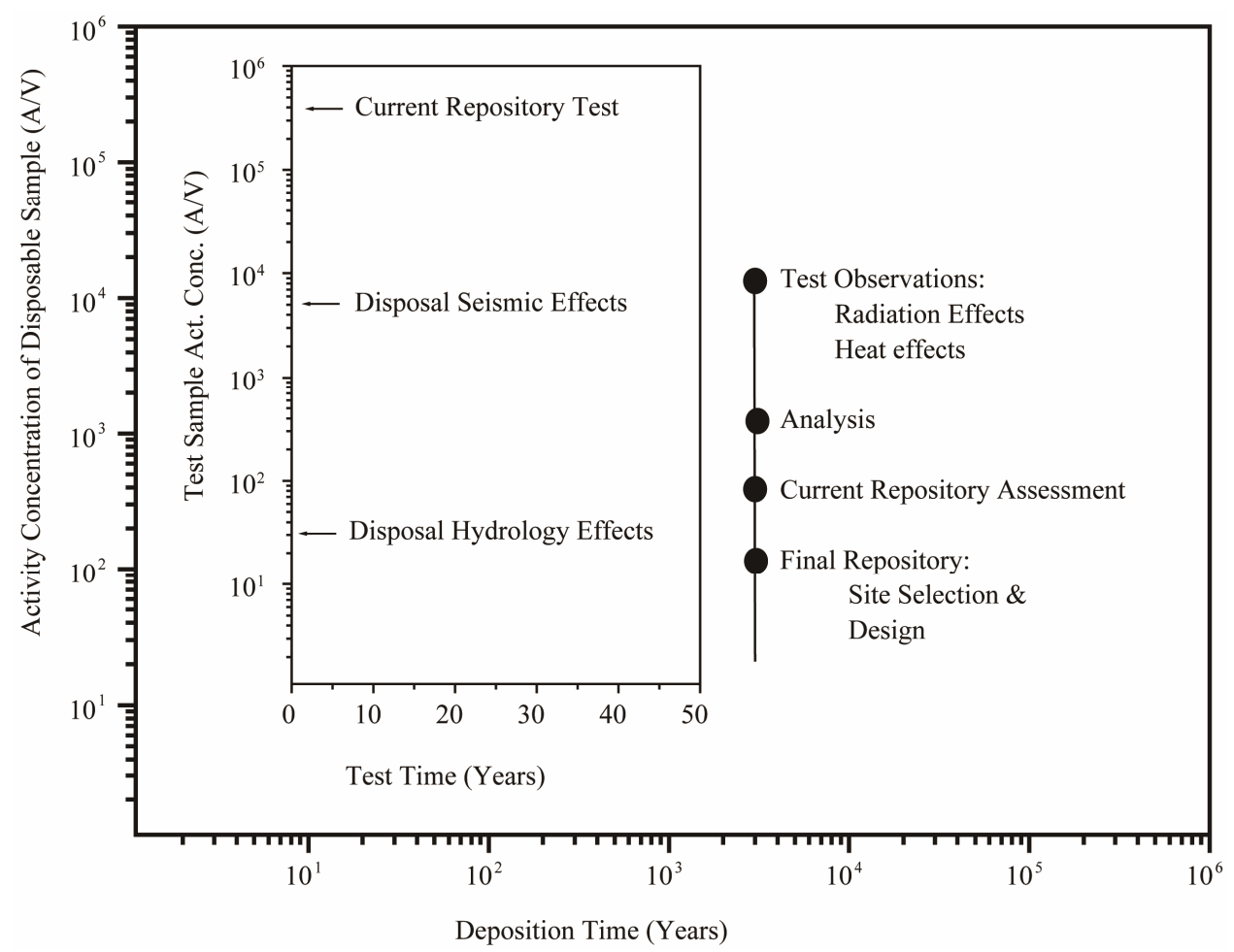

(b)

Figure 1. Conceptual model of a reliable scientific investigation (a) and high-level radioactive waste disposal plan.

close-circle coherent activities are necessary at small scale before fixing the implementation methods and techniques for a practical large scale final disposal of SNF or highlevel nuclear waste. Considering millions-year long radioactive and thermal life of SNF, at least 40 - 50 years are required to start large scale disposal. Considering great difficulties and extremely high cost of retrieval of disposed nuclear waste, political and social impacts also need to be analyzed carefully [11]. Figure 1(b) shows implementation plan or policy proposing small scale low activity sample disposal for studies of hydrology and seismic effects on disposed nuclear waste. Suitable sites with considerable hydrology and seismic activities need to be selected for these test disposals in order to understand impacts of failures due to lack of scientific understanding about hydrology and seismic history and future evolution. Figure 1(b) also describes how analysis of observations of test disposals can help in refining current repository design to achieve final practical disposal repository design and implementation plan.

Urgency for solution of final disposal of high-level nuclear waste is due to complications involved and multidisciplinary nature of the issue which will take long time 40 - 50 years to reach the stage of final disposal even after the practical selection of the final disposal site. Figure 2(a) shows the spent fuel cycle which is the major high-level nuclear waste. This simple schematic is based on the well-known facts and details are given by a number of authors, for example, [23-25]. Figure 2(b) shows general composition and forms of fission products and transuranium elements which are the most important for evaluation of a disposal activity. This figure is based on results by Buck et al. [26]. It is clear from Figure 2(b) that SNF is a very special type of waste due to high per- 


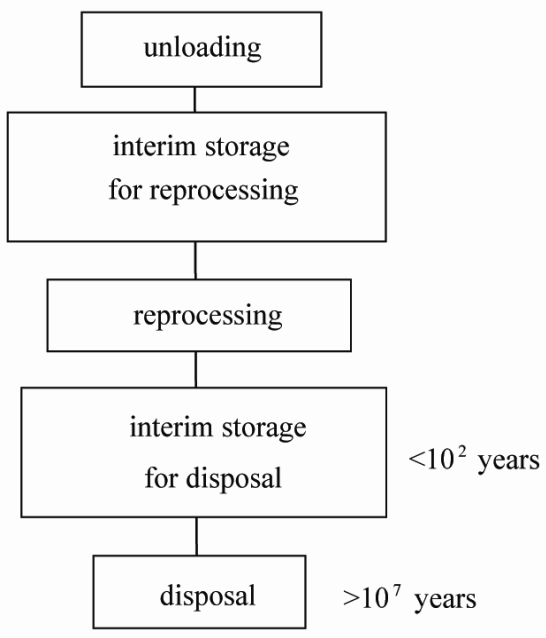

(a)

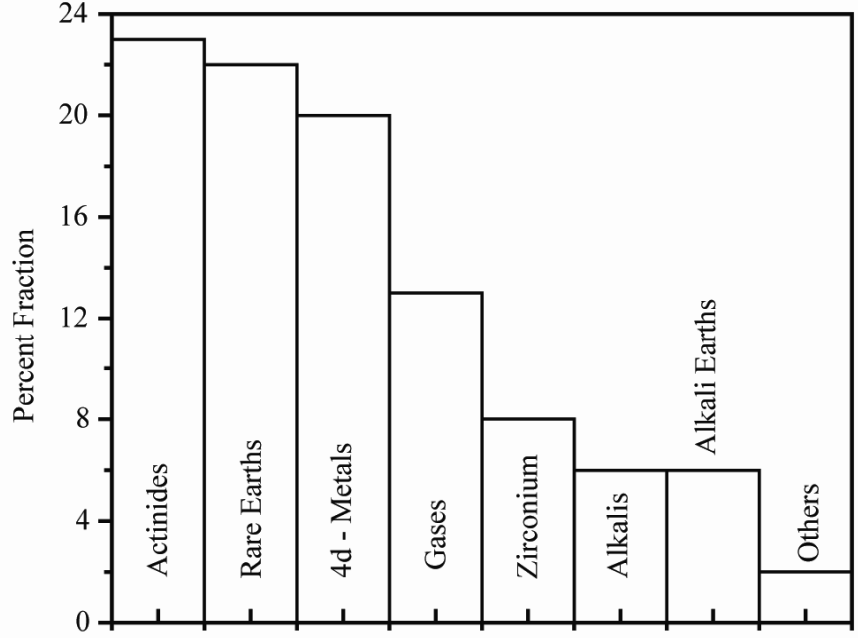

Fission Products \& Transuranium Elements

(b)

Figure 2. (a) Spent nuclear fuel cycle, and (b) General composition and forms of fission products and trans-uranium elements, which are most important in evaluation of disposal activity. Presentation is based on results by Buck et al. (2004).

centage of rare earth elements in it along with a quite considerable percentage of radioactive gases. These are very different characteristics from those of human safe environment. Major chemical alterations in SNF are gaseous and thermal evaporation, oxidation and dissolution of fuel pellets, and precipitation of secondary phases in changing spent fuel. These changes, based on well-known facts and results from Ref. [27] are represented by a schematic in Figure 3.

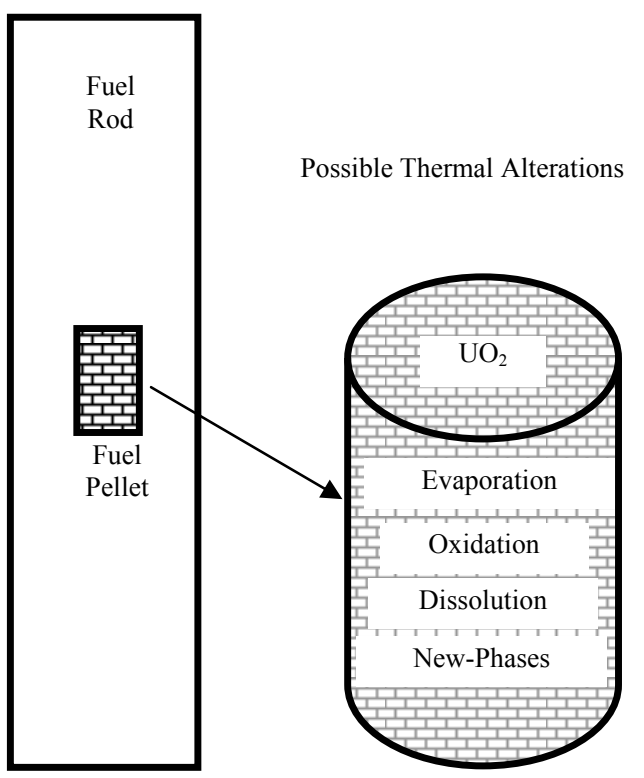

Figure 3. Thermal, structural and compositional alterations in SNF, which can cause significant consequences over longtime scale. This figure is based on generally known information in the field of nuclear engineering and that from Poinssot et al. (2005) and Ewing (2006).

\subsection{Proof of Safety: Global Hand to Hand Policy}

Can anyone on earth come up with a policy for HLW assuring a comprehensive safety of the global environment over a minimum time scale of 100,000 years? Present answer is "No". But, on the whole safe function of nuclear energy technology over a half century, despite the initial doubts about safety of nuclear technology, gives a hope. A three pronged strategy may be considered to build a trust in present and future safety of any HLW disposal policy. One is scientific basis of the disposal management policy; second the IAEA regulations for the disposal policy to assure global safety with minimum interference in any state's internal matters and third knowledge sharing among nuclear and related countries. Above mentioned strategy could provide a safety assurance with providing a chance of participation to anyone with legitimate capacity. Implementation of the above mentioned global hand to hand policy may find difficulties due to strategic nature of the issue and safety implications. This major inconvenience needs to be addressed on human grounds.

Responsibility of a failure of an HLW disposal policy and procedures, and first responders need to be defined with clarity. A comprehensive analysis is required to sort out the link between capacity and responsibility which may vary case to case and need to be carried out in the local context. But, common features of the issue of the link between capacity and responsibility should be dealt with at a global level to achieve legitimate general guidelines. Geological disposal of HLW is the best available choice. Figure 4 shows a guidance triangle for geological disposal of HLW. The most important aspects are the failure assessment of HLW containers and hydrology 


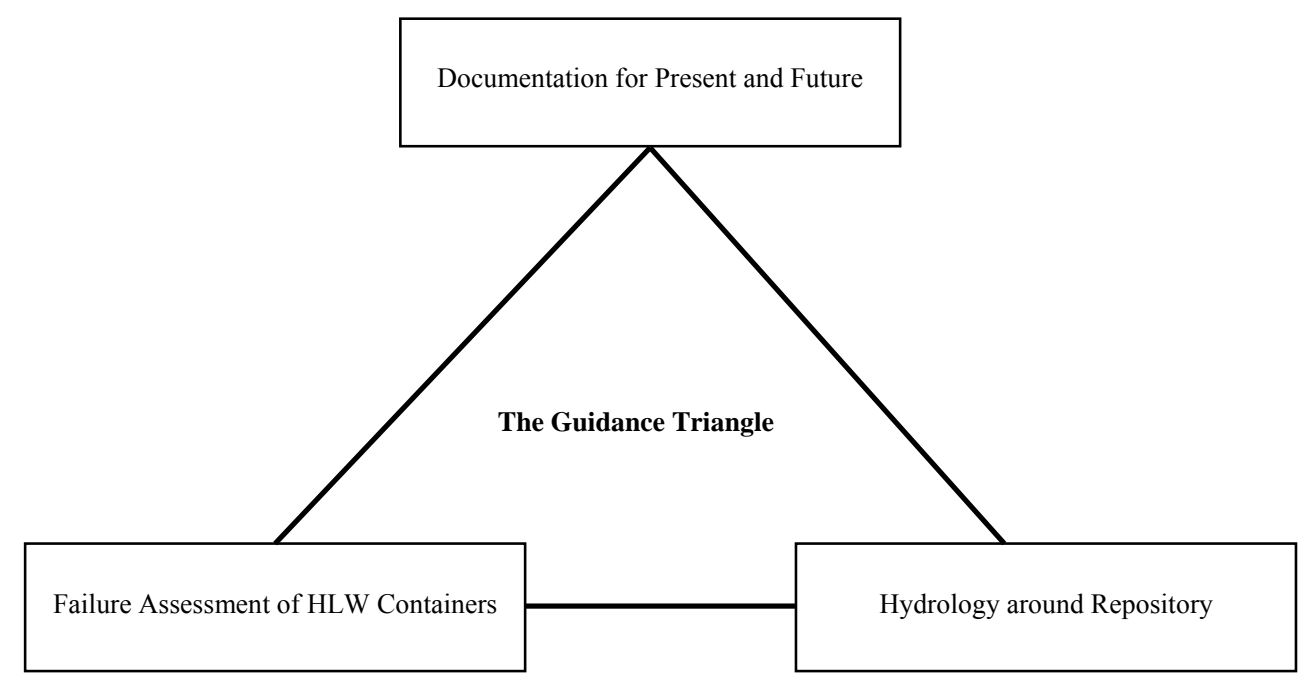

Figure 4. Guidance triangle to assure the keeping up of system for HLW geological disposal for more than 100,000 years.

around the repository site. Clear documentation of above mentioned activities, for present and possibly future, is also essentially needed. Method of lucid documentation is also an important issue.

\section{Disposal of Nuclear Waste}

The issue of disposal of SNF or high-level nuclear waste has been evaluated for decades now by nuclear scientists worldwide [21,25]. Ewing Considered options for SNF disposal include burial in ocean floor polar or ice hills, space disposal, keeping in interim storage facilities and more importantly, deep underground burial in special geological formations. Deep underground burial is being considered as safest in available options. Research areas involved in geological nuclear waste disposal are Materials Science \& Engineering, Nuclear Geology and hydrology. Despite the investigations cited above on materials and geology, correlated research activities are required for successful geological nuclear waste disposal, especially coupled investigations on underground geological formations, seismology and hydrology. Effects of radiations on confinement materials in final disposal are very important.

It is aimed here to highlight the major problems in the disposal of high-level nuclear waste like processed or unprocessed spent nuclear fuel. Problems involved are extremely complicated and requires conceptual, materials and other technical developments. Feared by complications, it is sometimes treated as un-solvable problem, which has imposed dark shadows on the future of nuclear power. To keep nuclear technology in work in future, related scientific community is working very hard to cope with the problems. Solution of this problem will bring conceptual and material developments, which will help in overall development of science and technology.
Geological disposal of SNF can only be successful by implementing multiple barrier strategy to confine the disposed waste and its effects far from safe environment to which living being have or may need to have contact in future. Figure 5(a) gives an overview of possible barriers to confine the disposed high level waste. Most important of natural barriers is a solid stable crystalline rock far from earth quake related fault lines. Engineered barriers include corrosion-resistant containers possibly of copper alloys and disposal architecture. Recently, a new method has proposed by Rana [17] for monitoring the radiation damage in nuclear waste containers using ion channeling. Ion channeling measurements are possible at ion beam facilities worldwide. A $1-3 \mathrm{MeV}$ helium ion beam can be employed to measure radiation damage in test crystalline samples placed in a section of a container wall as shown in Figure 5(b). Mathematical method for determination of structure collapse rate in container wall using ion channeling measurements is given by Rana ([17] 2008a). This method can be used to monitor the radiation damage in nuclear waste containers and to predict containment failures in near and far-future. Nature of single radiation damage in bulk and surface-layer of a typical solid is recently discussed by Rana $[17,18]$. Total radiation damage is accumulated effect of all radiations penetrated in to a target or containment materials, with different radiations causing different magnitude and type of damage. Thermal and chemical stability $[19,21]$ of containment materials is an important in selection of materials to be used in containment of nuclear wastes.

Status comments on major aspects of final disposal are described below in the form of a few points. 1) Initial radiation strength per unit spent nuclear fuel depends on burn-up the fuel, but extremely high for any living being without best available shielding arrangements [28]; 2) Radioactivity decay time scale for SNF of the order of 

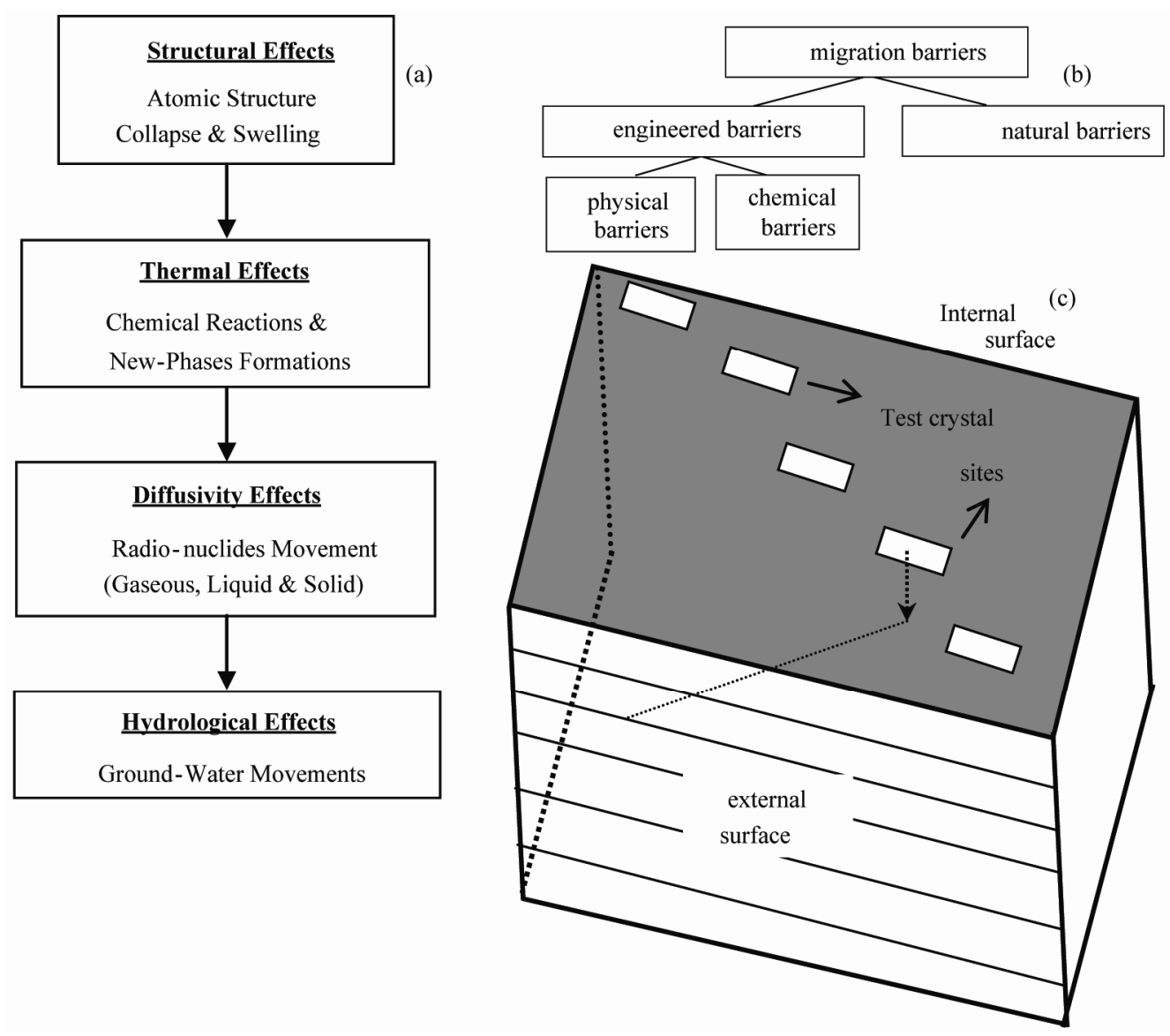

Figure 5. (a) Radiation effects on containment materials and environment; (b) Migration barriers in repository design; and (c) Section of the nuclear waste container wall for installation of radiation damage test crystal samples.

geological time scale, which is up to millions of years; 3) Forms of radiations from SNF include charged and neutral particle rays, and electromagnetic radiations; 4) Decay of radioactive elements in SNF is accompanied with the release of energy, most of which is transformed into heat. SNF is a heat source, which can harm integrity of its disposed packages; 5) Gaseous nature of radioactive products is of great concern. Thirteen percent of fission products and trans-uranium elements are gases, which has higher danger of leakage and mobility to the objectively safe environment; 6) Direct disposal of SNF will be cheaper [29], but it is like wasting potential source of energy; 7) Transmutation decreases the danger level of SNF, but does not solve the problem completely. Final disposal will still be needed [28]; 8) Ideally, retrievablility after disposal is required. But, its assurance is difficult due to involvement of unexpected natural happenings like earth-quakes.

Figure 6(a) shows the outline of the rock-integration nuclear waste burial design by Maki and Ohnuma [15]. Figure 6(b) shows present modifications to the design shown in Figure 6(a) with objective to achieve improvement regarding pressure build up due to complete block- age of underground water flow. Leaving open channels or tunnels for controlled water flow through buried waste. This water flow through open channels or tunnels will also serve as monitoring test about any leakage from waste packages. These channels will avoid water pressure build up beyond a critical limit and if a considerable leakage is observed in water through these channels, nuclear waste burial design should allow the blockage of these water channels. Another notion of chemical heat sink (Figure 6(b)) is introduced, which if incorporated in burial design, can keep the temperature of nuclear waste under limit. This chemical heat sink is a compound chemical material, which will decompose by absorbing heat emitted by nuclear waste. Water flow through proposed channels in the buried waste will also cool nuclear waste.

\section{Radiation Effects}

\subsection{Radiation Damage}

Degradation of spent fuel itself and containment materials due to radiation effects is a very considerable concern. Intensive radiation exposure causes dramatic degradation in structural and strength related properties of materials 


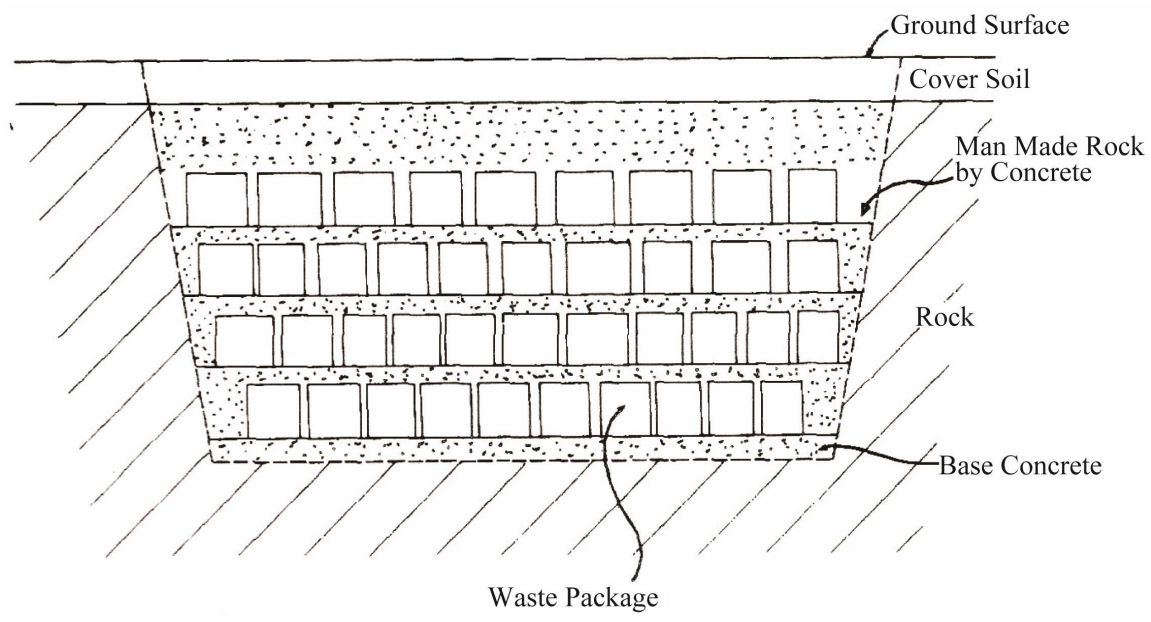

(a)

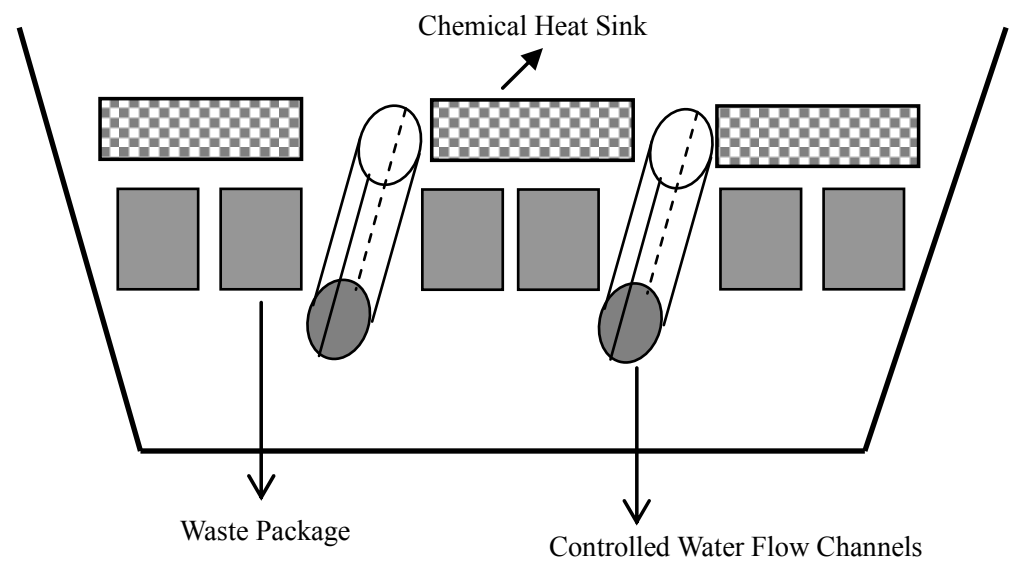

(b)

Figure 6. (a) Design of rock integration nuclear waste burial facility by Maki and Ohnuma (1992) and (b) Modifications to the above-mentioned design to assure integrity of buried waste.

leading to their failure when damage exceeds a certain limit. A number of aspects of radiation damage have been recognized and being studied over more than 60 years. Radiation damage leaves four types of effects on any material, i.e. electronic and optical which are not significant in nuclear waste containment, physical and chemical. Physical and chemical effects need to be considered. A variety of radiations continue penetrating waste containment and the aggregated effects over decades thus are important for determination of containment failure. A single radiation, especially energetic charged particle, causes a compound spike [30] in the target material. This compound spike arises as a consequence of a Coulomb explosion and a thermal spike, and decays very quickly within $10^{-12} \mathrm{~s}$. These physical impacts result in the form of heat emitting out into the neighbouring material of the cylindrical zone through which radiation passes. The increased temperature, due to continuous radiation spikes, produce chemical changes like formation of new material phases. Figure 7 shows the generalized view of expected radiation effects on containment materials to be used in nuclear waste disposal.

Here, a very brief account of basic physics of radiation damage is being given which may help in implementation of the method for the radiation damage monitoring described above and interpretation of experimental observations of the method. A charged particle or radiation traveling in a solid creates a superheated cylindrical zone with a modified structure containing defects of various types and size. In the inner dotted cylindrical zone in Figure 8, bulk atomic flow takes place whereas in the outer shell only individual atomic flow is occurred. A fresh radiation damaged zone in a solid is highly unsteady in time and after reaching thermodynamic equilibrium it becomes an inhomogeneous structure. The energy deposited by the incident radiation in a cylindrical volume around the path is non uniform. It decreases exponentially along radial direction whereas distribution along axis of the cylinder depends on energy of the particle. For an $\mathrm{MeV} / \mathrm{u}$ ion, it has a maximum at a depth into the 


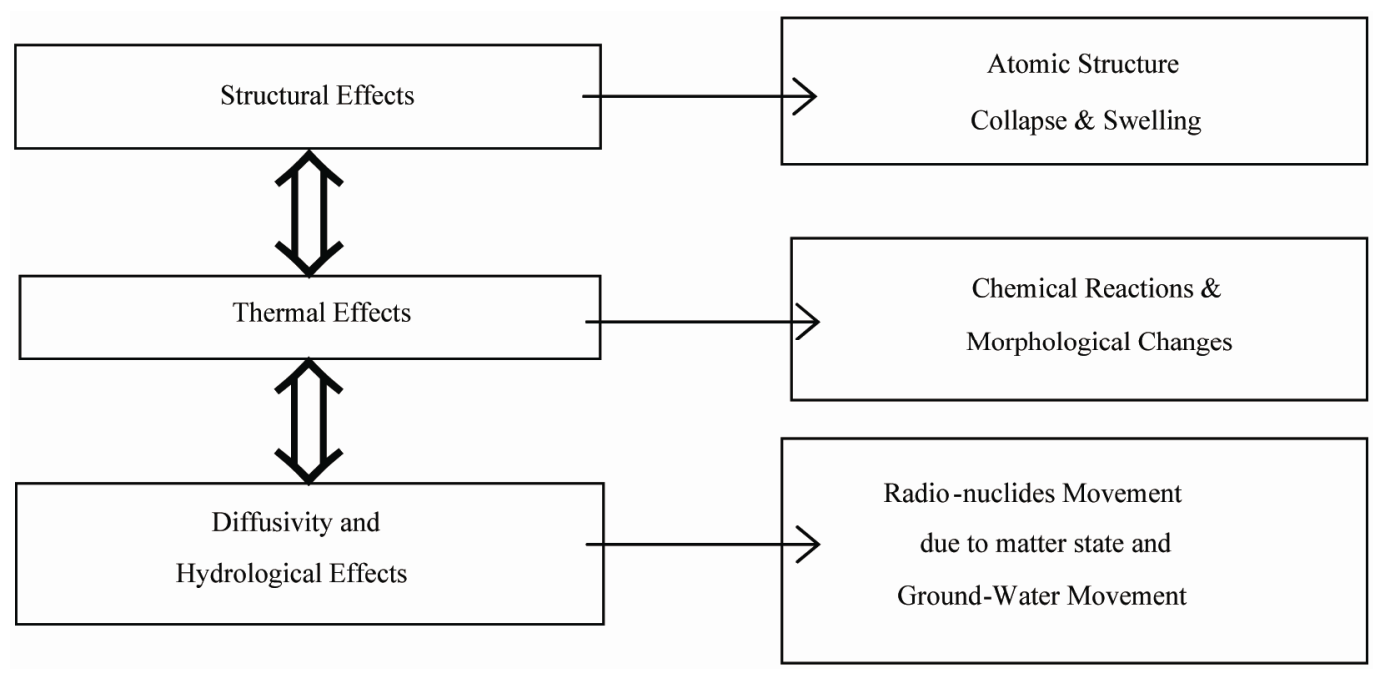

Figure 7. Radiation effects on containment materials and environment.

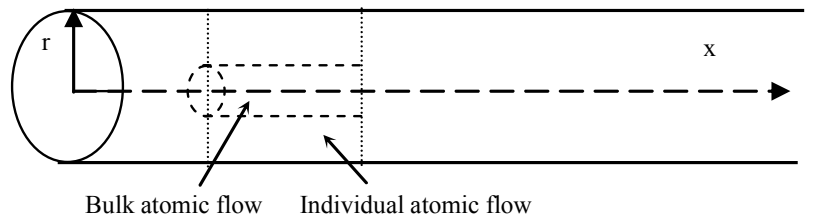

Figure 8. Radiation damage produced by a charged radiation in a typical solid, showing cylindrical zones of bulk and individual atomic flows. Parameters are defined/shown in this figure for the purpose of mathematical description of the problem.

target.

Interaction of a radiation with a solid target can be treated as a compound spike including partial roles of both thermal and Coulomb explosion spikes. Fractional roles of both spikes depend on atomic and electronic structure of the target and density of deposited energy in it by the incident radiation. An incident radiation is scattered by the atoms in the target as it interacts with them and deposits energy. Weak scattering of incident radiations by light target atoms does not significantly deviate incident particles from their straight trajectories while the target atoms recoil considerably, damaging the detector. Heavier atoms scatter incident particles through wide angles, significantly deviating them from their straight paths while the target atoms recoil weakly, producing less damage. So, it is important to notice that radiation damage mechanism in a target composed of light atomic species is different from that composed of heavier atoms. Compound impacts of a number of radiations in a target, incident within a specific distance, superimpose with one another in both constructive and destructive manners. Part of the damage produced by one radiation is extended due to the damage produced by another radiation within a few hundred nanometers. Nuclear waste containers and related materials are exposed to radiations with a wide spectrum of ionizing power including fission fragments of very high ionizing power and gamma rays of comparatively very low ionizing power.

\subsection{Measurement of Radiation Damage}

\subsubsection{Brief Description of the Single Scattering Method}

Radiation damage in a piece of a crystal (a test sample say Si, Ge, Zr or Zircon) exposed to radiations will carry information about total radiation exposure of the crystal. So, proton or helium ion channelling measurement of radiation damage in the test sample, placed in the crystalline or amorphous immobilizing containment, can in principle yield considerably complete information about total radiation exposure. A calibration between structure collapse rates of test sample and container wall material will provide the structure collapse rate of the containment material. Figure 9 is the schematic showing components on an initially channelled proton/ion beam in a crystal. This figure is modified from the original [31]. The total random fraction of the beam $\chi_{T}(x)$ is the sum of the random fraction of the beam in the crystal, $\chi_{R}(x)$, reaching depth $x$ and fraction of the beam randomized by the defects in the depth step $x+d x, \chi_{D}(x)$,

$$
\chi_{T}(x)=\chi_{R}(x)+\chi_{D}(x)
$$

The component $\chi_{D}(x)$ may be written as,

$$
\chi_{D}(x)=\left[1-\chi_{R}(x)\right] \frac{f n_{D}(x)}{n}
$$

where $n_{D}(x)$ is atomic concentration of defects, $n$ the total atomic concentration, $f$ the defect scattering factor. The factor $f$ accounts for the fact that all defects do not contribute equally and may have different number of scattering centres [31]. For randomly displaced atoms 

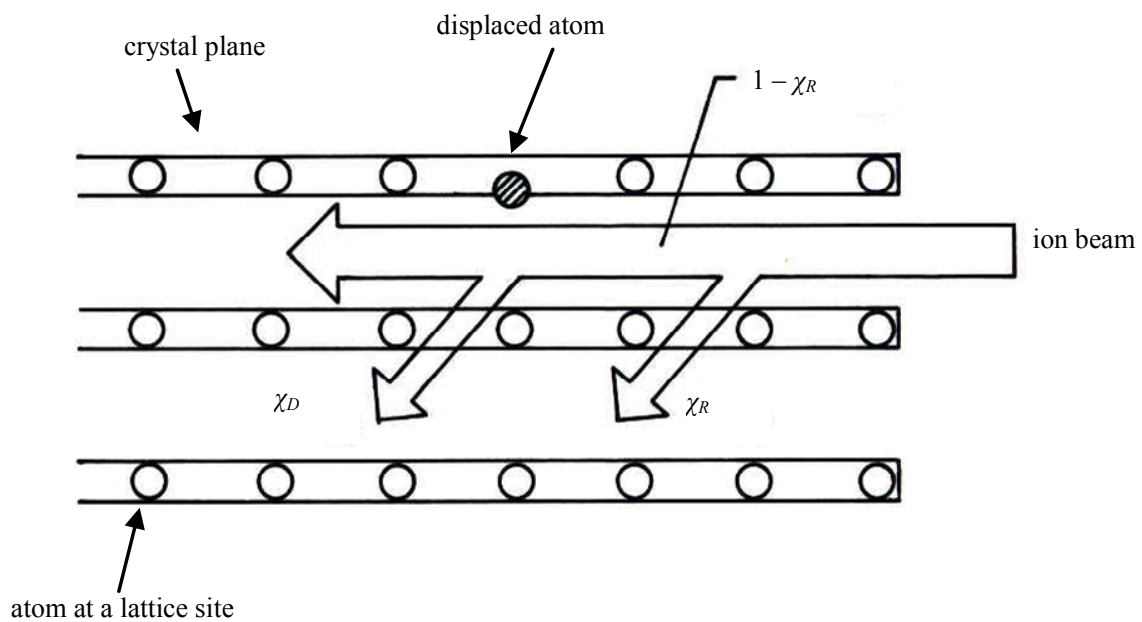

Figure 9. Dechannelling of channelled beam due to defects present at an arbitrary depth. $\chi_{R}$ and $1-\chi_{R}$ are random and channelled fractions of the beam reaching the considered defect layer.

(called isolated interstitials), the value of $f$ is 1 . The quantity $\chi_{R}(x)$ is not a measurable quantity. It is the sum of random fraction in the perfect crystal $\chi_{V}(x)$ and the random fraction resulted from the dechanneling by all defects along the depth $0-x$.

With single scattering approximation, $\chi_{R}(x)$ is given by

$$
\begin{aligned}
\chi_{R}(x)= & \chi_{V}(x)+\left[1-\chi_{V}(x)\right] \\
& \times\left[1-\exp \left\{-\sum_{i} \int_{0}^{x} \sigma_{D}^{i} n_{D}^{i}\left(x^{\prime}\right) \mathrm{d} x^{\prime}\right\}\right]
\end{aligned}
$$

For the case of very small defect concentration, $\chi_{R}(x)$ is given by,

$$
\chi_{R}(x)=\chi_{V}(x)+\left[1-\chi_{V}(x)\right] \times\left[\sum_{i} \int_{0}^{x} \sigma_{D}^{i} n_{D}^{i}\left(x^{\prime}\right) \mathrm{d} x^{\prime}\right]
$$

where $\sigma D$ is the dechannelling factor of a certain type of defects along the beam path $0-x$. The quantities $\chi_{T}(x)$ and $\chi_{V}(x)$ are measurable quantities in backscattering channelling experiments and yield the quantity $\chi_{D}(x)$ needed to determine defect density at depth $x$ in a crystal using Equations (2) and (3). The above formulation with single scattering dechanneling approximation is only valid for small defect densities (less than $\sim 10 \%$ of lattice sites constitute defects) [31]. For higher defect densities, the possibility of multiple scattering dechanneling needs to be incorporated.

\subsubsection{Incorporation of Multiple Scattering}

For multiple scattering only, the quantity $\chi_{R}(x)$ takes the following shape,

$$
\begin{aligned}
\chi_{R}(x)= & \chi_{V}(x)+\left[1-\chi_{V}(x)\right] \\
& \times\left[\exp \left\{-\sum_{i} \int_{0}^{x} \sigma_{D}^{i} n_{D}^{i}\left(x^{\prime}\right) \mathrm{d} x^{\prime}\right\}^{-1}\right]
\end{aligned}
$$

Following the recent work by [32], combining both single and multiple scattering mechanisms, $\chi_{R}(x)$ becomes (see Equation (8))

where $g(\eta)$ is an attenuation function and $\eta=\int_{0}^{x} n_{D}(x) \mathrm{d} x$ is the areal density of defects.

$L_{n}=\ln (1.29 \varepsilon)$ and $\varepsilon$ is reduced energy used in calculations of nuclear stopping power (Lindhard, 1964). The attenuation function $g(\eta)$ is given by [32],

$$
g(\eta)=1-\exp \left[-\left(\sum_{i} \int_{0}^{x} 2 \sigma_{D}^{i} L_{n} n_{D}^{i}\left(x^{\prime}\right) \mathrm{d} x^{\prime}\right)^{-1}\right]
$$

Figure 10 shows selected results of $2 \mathrm{MeV} \mathrm{He}$ ions channelling along a $<100>$ axis [33]. It is clear from this plot that single scattering dominates for low values of areal defect density $\eta$ (named here Regime I) and starts losing significance after $\eta$ increases beyond a certain value at the cost of increase in multiple scattering (Regime II). In Regime III, only multiple scattering takes place. Equation (6) would be valid in all three regimes of $\eta$.

\subsubsection{Physical Realization of Channeling Method}

Depending upon the radiation flux and temperature of the

$$
\chi_{R}(x)=\chi_{V}(x)+\left[1-\chi_{V}(x)\right] \times\left\{\left[1-\exp \left\{-\sum_{i} \int_{0}^{x} \sigma_{D}^{i} n_{D}^{i}\left(x^{\prime}\right) \mathrm{d} x^{\prime}\right\}\right] \times g(\eta)+\exp \left[-\left(\sum_{i} \int_{0}^{x} 2 \sigma_{D}^{i} L_{n} n_{D}^{i}\left(x^{\prime}\right) \mathrm{d} x^{\prime}\right)^{-1}\right]\right\}
$$




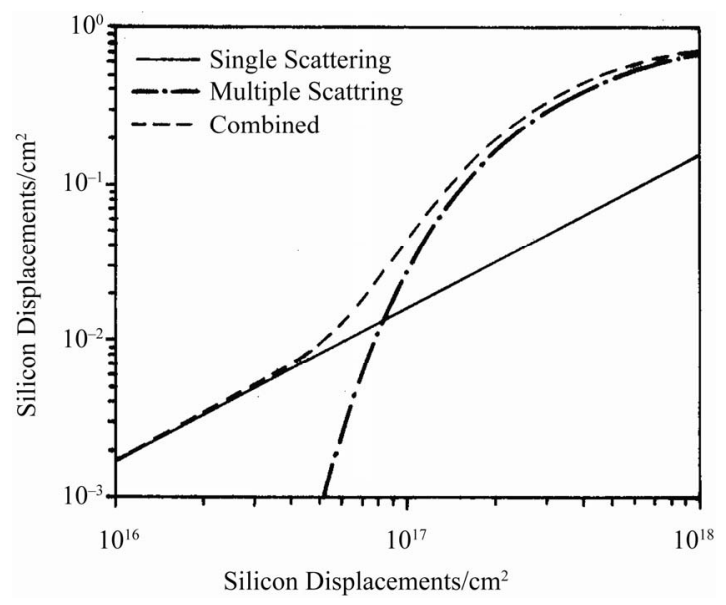

Figure 10. Dechanneling probability due to single scattering and multiple scattering for $2 \mathrm{MeV} \mathrm{He}$ ions in silicon along $<100>$ axis (Shao, 2008).

containment wall, any crystal fulfilling certain conditions can be used. These crystals ( $\mathrm{Si}, \mathrm{Ge}, \mathrm{GaAs}$ and $\mathrm{GaN}$ ) are available in the market. Diamond has high melting temperature, but can not be used due to lower channeling yield. Information about these commercially available crystals is easily available (Website, University Wafers, http://www.universitywafer.com). Specific dimensions of the test crystal depend on channeling measurement facility and design of the container. Typical dimensions of a test crystal sample are shown in Figure 11(a). If the container material is crystalline and a sample of the same material is used as a test sample, radiation damage in the test sample will be same as in the container material. Details about channeling measurements of defects in GaN crystals produced high temperature exposure are given by Rana et al. $[19,21]$. The same defect quantification procedure can be used for measurement of radiation damage in the test crystal sample. If container material is amorphous or a crystal on which channeling measurements are not possible, a relationship or a calibration between structure collapse rate of the test crystal and damage in amorphous containment material is required. Both test crystal and container material will undergo irradiation in the same environment, then channeling measurements will be performed on crystal, whereas some other method like X-ray photoelectron spectroscopy or XPS will be used on amorphous container material to determine the concentration of broken bonds. The relationship between concentrations of atoms displaced from lattice sites in the test crystal is determined using channeling and the broken atomic bonds in the container amorphous material will serve as a calibration. At present ion beam facilities worldwide, $1-3 \mathrm{MeV}$ helium ion beams are available, crystal layer up to a couple of microns depth can be investigated for defect measurement using ion channeling. If it is required to determine radia-

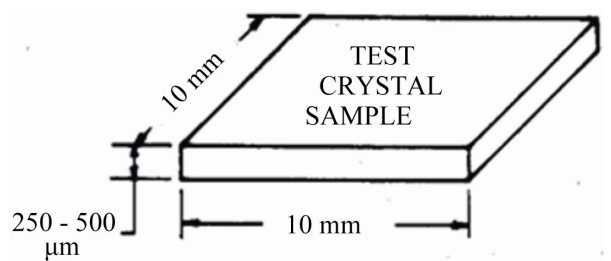

(a)

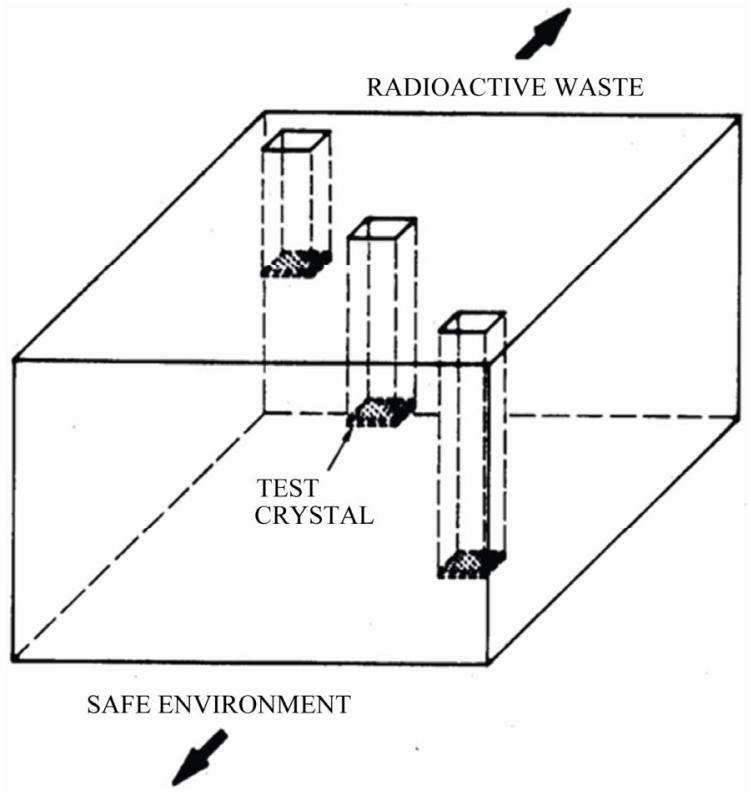

(b)

Figure 11. (a) Dimensions of the test crystal sample; (b) Section of the nuclear waste container wall for installation of radiation damage test crystal samples.

tion damage at 3 different sites in the container wall, five identical test crystal samples will be placed at objective sites as shown in Figure 11(b). After exposure, defect concentration in surface layer of thickness $1-3 \mu \mathrm{m}$ in all test samples will be measured using ion channeling and measurements will give intensity of radiation damage at crystal sample sites in the containment material. Nature of single radiation damage in bulk and surface-layer of a typical solid is recently discussed [17]. Total radiation damage is accumulated effect of all radiations penetrated in to a target, with different radiations causing different magnitude and type of damage.

\subsection{Co-Use of Channeling with Other Techniques}

This paper discusses which techniques can be co-used with channeling to increase the accuracy of the measurement of the radiation damage in nuclear waste containers. Nuclear magnetic resonance (NMR) is an attractive technique for radiation damage measurement as it is element specific and is sensitive to both structures in crystalline and amorphous domains in a sample [32]. 
Using ion channeling and NMR together will make a dual radiation damage detection and measurement system. The displacement of low $\mathrm{Z}$ atomic species (like hydrogen) in the test crystal (which can not be measured or can only be measured with low detection efficiency using backscattering ion channeling) can be measured using NMR. Another scheme for short and long term measurement of radiation damage in nuclear waste containers is presented here. In this scheme, ion channeling and nuclear track detection technique are used as two independent techniques for radiation damage measurement. A wide spectrum of radiations ( $\alpha, \beta, \gamma$ and fission fragments etc.) enter the container wall from the HL nuclear waste. These defects diffuse in the material of the wall, coalesce and make extended defect structures. Production of defects and their reaction continue as radiations enter the material continuously. A typical defect structure of the container wall is three fold: A part of the material is severely damaged, another part gently damaged and the remaining undamaged. Figure 11(a) shows a section of the nuclear waste container wall. Channeling and nuclear track detectors can be installed in the wall as shown in Figure 11(b). Both nuclear track detectors (like CR-39) and channeling detectors (test crystals like Si and $\mathrm{Ge}$ ) will provide short term radiation damage monitor. These measurements will also provide an inter-calibration of two techniques, which would help in reliable quantification of defects in the container material at different points in time. Long term (days to years) monitoring of the radiation damage will be carried out by channeling method only.

\section{Thermodynamic Equilibrium and Multi-Barrier Isolation}

Thermodynamic equilibrium is a state of a system related to the minimum of the thermodynamic potential. Thermodynamic potential is the Helmholtz free energy (U TS) for systems at constant temperature and volume whereas the Gibbs free energy (H - TS) for systems at constant pressure and temperature. $\mathrm{U}, \mathrm{T}, \mathrm{H}$ and $\mathrm{S}$ are, respectively, internal energy, absolute temperature, enthalpy and entropy. Minimum of thermodynamic potential is characterized by states of thermal equilibrium, mechanical equilibrium and chemical equilibrium of the system. Ideally, nuclear waste should be disposed in a way that it becomes in thermodynamic equilibrium with the environment and remains the same for almost forever without losing its original integrity.

Success probability of SNF disposal would increase by implementing multiple barrier strategy to confine the disposed waste and its effects far from safe environment to which living being have or may need to have contact in future. The definition of human vulnerability in such a case is given in Figure 12. Most important of natural barriers is a solid stable crystalline rock far from seismic zones. Engineered barriers include corrosion-resistant containers possibly of copper alloys (containing mainly copper along with $\mathrm{Al}$ : $5 \%$ to $9 \%$; $\mathrm{Ni}: 0.5 \%$ to $4 \%$; Fe: $0.5 \%$ to $4 \%$; $\mathrm{MN}$ : $0.1 \%$ to $3 \%$; $\mathrm{Ti}: 0.001 \%$ to $1 \%$, $\mathrm{Co}$ : $0.001 \%$ to $1 \%$; and B: $0.001 \%$ to $0.1 \%$ ) [34] and disposal architecture. Regular drilled-hole monitoring in the buffer zone and sampling the leached activity before and after earthquake can establish underground faults produced due to earthquake. Nuclear waste containment and the over-all repository environment should ideally be as close as possible to thermodynamic equilibrium, meaning unlimited stability, similar to natural metal deposits within Earth's crust [35].

\section{Environment Ethics}

Some of major considerations in evaluation of ethical issues related to safety of nuclear waste disposal are clarity of the policies, policy awareness of individuals involved, natural response to nuclear fear/risk factor and valid legal system to sue charges. Central specific ethical issues are summarized as a set of disposal activity start-up questions [3,4]: 1) Have the persons employed/involved been given the free informed consent to the risk involved? 2) Who bear major responsibilities in waste disposal and who is responsible for what? 3) Are the distributions of risks and benefits equitable? 4) Have individuals been informed about control over the risk? 5) Are assessment about reliability of materials and methods involved are made? 6) What are the third parties who can be held responsible for bringing in risk? 7) Evaluation of costs and benefits of intervention measures? 8) Are the plans of compensation for exposure to risk justified? 9) How will an emergency be handled? Generalizing theme build up by above questions, it may be said that issues like consent, equity, control and responsibility are essential ethical considerations for radiological protection policy [36].

It would be interesting to know how above issues or questions about nuclear waste disposal are incorporated in policy making and its implementation. Only thoughtfully critical and multiply reviewed process of policy

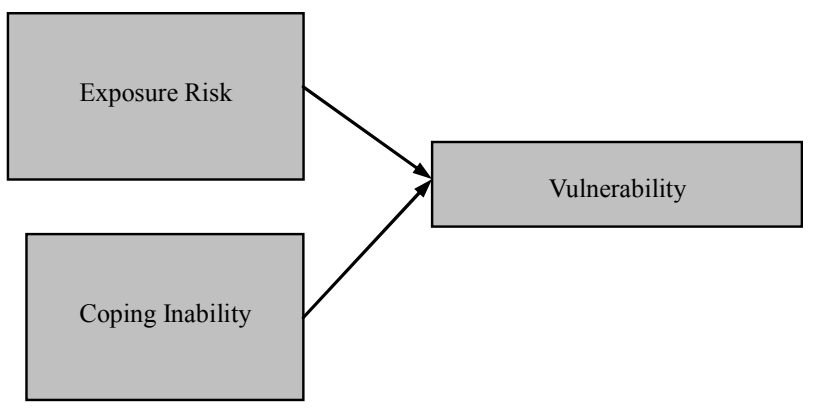

Figure 12. Definition of human vulnerability. 
analysis can achieve this. Ethical issues are closely linked with scientific or technical know how about procedures involved. So, a trustworthy research is needed to finalize ethical aspects of high level nuclear waste disposal. Evaluation of risk faced by far-future generations due to present disposal of high level nuclear waste is also of great importance and equally valid ethical issue as for the case of present generation. Real problems are associated with predictions about level and nature of risks faced by future generations and their response to this problem, especially in case of disposal failures.

It would not be wise to dispense with highly radioactive material and to hope that either nature or future generations of humans will not bring it into the biosphere somehow. In principle, we should ensure that even if detail of nuclear waste disposal is lost and does not reach future generations, still they or their environment is not exposed to disposed waste at all. Nuclear waste disposal in one country can quite possibly affect biosphere in the neighbouring countries. Pakistan's two neighbouring countries are among the countries seeking sizeable future nuclear energy programs [37] whereas Russia has offered its land for a multinational nuclear waste repository [38]. These activities may pose questions of nuclear security and environmental justice which Pakistan would need to address. Nuclear waste disposal is not a solely internal matter of any country. Activity of nuclear waste disposal may have strong local, regional and even global implications. Regional and global implications would become considerable for the cases of severe failures of disposal scheme.

\section{Conclusions, Final Remarks and Perspective}

Present status of different aspects of spent nuclear fuel disposal is overviewed briefly, but comprehensively. Time framework and time-line plan or policy for high- level radioactive waste disposal are described and discussed. A new concept of chemical heat sink is introduced to consume the heat emitted by spent nuclear fuel without affecting the integrity of waste containment. Conceptual model description of major issues of spent nuclear fuel disposal is given along with scientific discussion and comments with focuses of materials, geology, seismic and hydrology aspects. Modifications to a proposed geological disposal of nuclear waste are proposed with scientifically supported arguments.

Paradox of HLW casts shadows on nuclear future. Best science with highest functionality can help solving this problem. Need of ultimate disposal of HLW is an inconvenient truth facing the humanity. This multi-tiered problem should be dealt with IAEA coordination among nuclear states to sort out short and long-term aspects of the HLW disposal. IAEA coordination would be aimed at sharing of the cutting edge knowledge to assure safety of the global environment. Environment is indivisible and the long-term radiological obligations require a global solution and makes it natural.

Although no repository around the globe is ready for geological disposal of nuclear wastes, some developments, mainly in conceptual and plan domains, were made in last couple of decades. Table 2 summarizes the present plans for high-level nuclear waste repositories. Tabulated details show the sensitivity of the subject and requirement of the decades-long considerations before start up of implementation of any disposal policy. In nuclear waste disposal matters, four considerations are very important which are radiation strength, mean life, environment contamination and traditional ethical values.

Ethical values here refer to rightness or wrongness of our actions. Considering above discussion about high-level nuclear waste disposal, a long time in decades would be needed in evaluation of repository location, design and precautions before start up of disposal. Careful record

Table 2. Plans for high-level nuclear waste repositories (Andersen et al., 2004).

\begin{tabular}{llll}
\hline \multicolumn{1}{c}{ Country } & \multicolumn{1}{c}{ Geological medium } & Estimated opening & \multicolumn{1}{c}{ Status } \\
\hline Belgium & Clay & 2035 or later & Searching for site \\
Canada & Granite & 2035 or later & Reviewing repository concept \\
Finland & Crystalline bedrock & 2020 & Site selected (Olkiluoto) \\
France & Granite or clay & 2020 or later & Developing repository concept \\
Germany & Salt & Unknown & Moratorium on development \\
Japan & Granite or sedimentary rock & 2030 or later & Searching for site \\
Russia & Not selected & Unknown & Searching for site \\
Sweden & Crystalline rock & 2020 & Searching for site \\
Switzerland & Crystalline rock or clay & 2020 or later & Searching for site \\
United Kingdom & Not selected & After 2040 & Delaying decision until 2040 \\
United States & Welded tuff & 2010 & Site selected (Yucca Mountain) \\
\hline
\end{tabular}


keeping (including details of professionals involved) of all nuclear waste disposal evaluations should be practiced so that investigation of possible accident/emergency could be carried out with transparency.

Clear demonstration about safety aspects of nuclear waste management would help in gaining public and political confidence in any possible scheme of permanent nuclear waste disposal. A common public desire is retrievability of finally disposed wastes in case repository fails to isolate wastes from the live environment. Desire of retrievability is in direct contradiction with the principle of final disposal and adds serious complexities to the problem. Public resistance against nuclear waste repository [39] at Yucca Mountain is a typical example showing the complexities involved. Figure 13 shows a simplified picture of the Swedish plan for geological disposal of nuclear wastes [40]. Different objects in the figure, showing steps of the disposal procedure, are explained with the inset text. The figure differentiates high radioactivity wastes from low and intermediate radioactivity wastes which require different disposal procedures.

Fukushima disaster (Figure 14) on March 11, 2011 and Japan's efforts (Figure 15) in collaboration with the whole world in dealing with it offers a knowledge and strategic framework regarding the preparedness for the next possible accident of this nature. Science, engineering, technology, social and political spheres from around

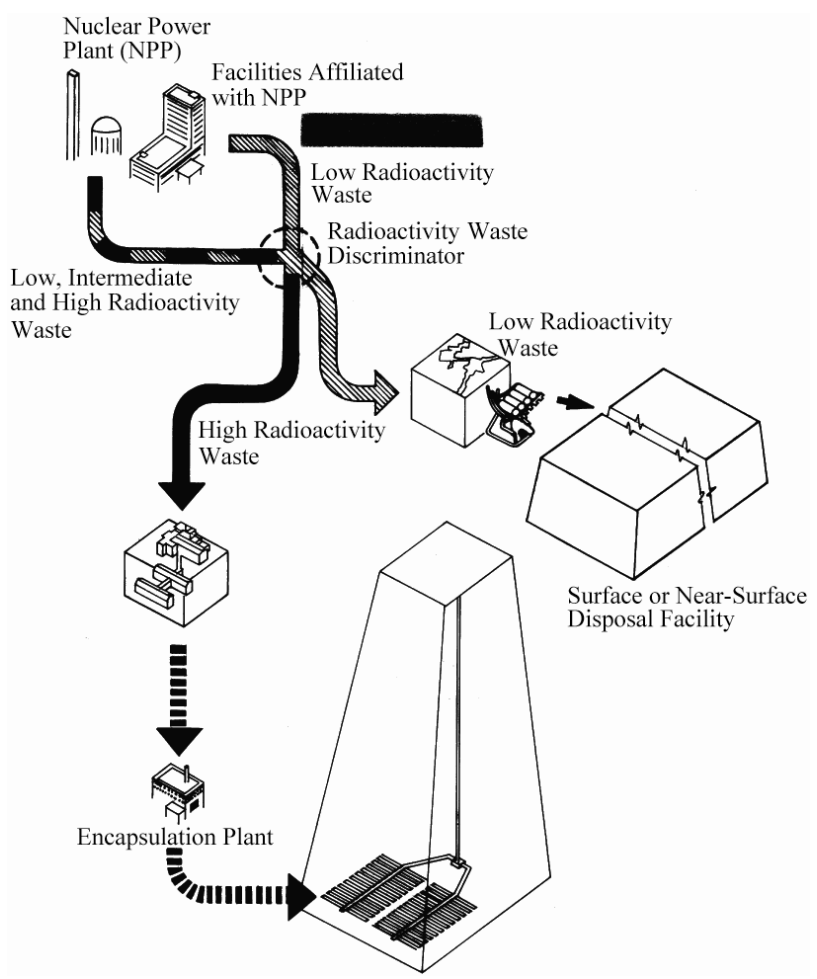

Figure 13. A simplified picture of the Swedish plan for geological disposal of nuclear wastes Thegerström [40].

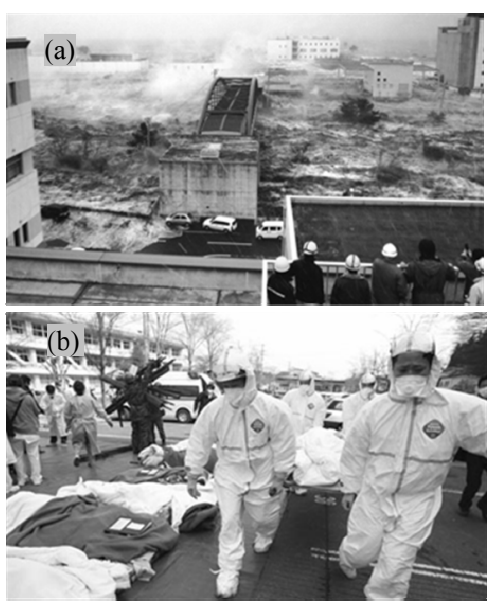

Figure 14. (a) A picture of Fukushima disaster [41] and (b) Japan's immediate response to it [42].

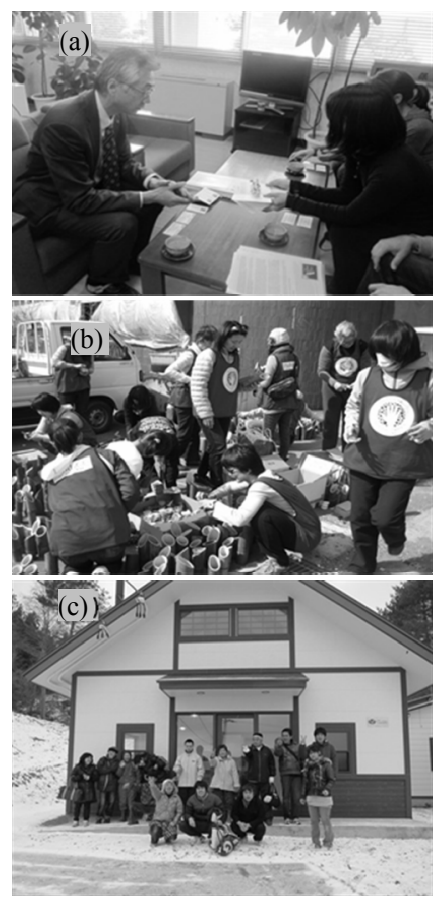

Figure 15. Three pictures [42] showing Japan's systematic response to the Fukushima disaster during which it collaborated with several countries from around the world.

the world must join together to map the response plan and its adequate execution, possibly of spontaneous nature, in facing such accident anywhere in the world. Such a grand alliance can be a solution to happenings of "type $\mathrm{N}$ " as it reduces the cost and the chance of failure. An incident of "type N" is a nuclear event which has a very low happening frequency but a high level of serious implications. There had been dangers in air travelling and electricity supplies, but they are technical safe and sound now. Conscious, careful and continued efforts with the joint wisdom could provide the concrete solution to the 
challenge of the nuclear safety by assuring the dreamlike reality line of "no failure in the nuclear technology". Putting aside the political games, this noble cause of nuclear safety is doable. Achieving this cause or goal will be a truly remarkable and historical pride for the humanity. Fukushima disaster and responding efforts have revealed strengths, weaknesses and the improvement road map for the nuclear safety.

\section{Acknowledgements}

Discussions with and help by colleagues Prof. E. U. Khan, Rahman Blocks, International Islamic University, Misri Water Lanes, KASHMIR Highways, H-11/4, Islamabad, Mr. Farooq Jan, Mr. Muhammad Ayub, Mr. Muhammad Ramazan, Dr. Noor Muhammad Butt, Mr. Abdul Ghani, Mr. Neik Emmal, Dr. Parveen Akhter, Mr. Muhammad Akhtar, Ms. Naila Siddique, Ms. Sana Malik, Dr. Mati, Dr. Usman Rajput, Mr. Qamar Abbas and others (Drafts-Men), Mr. Raja A. Ghaffar, the recently deceased colleague Nazir Maseeh, Mr. Yusuf, PIEAS, Islamabad, Dr. H. R. Hoorani, Shahdara GAP Valley, NCP, Islamabad, Mr. Muhammad Zulfiqar, NESCOM, Islamabad, Mr. M. Asad, KRL, Rawalpindi, Dr. Rakhshanda Bilal, SUPARCO, Islamabad, Ms. Bushra Elyas, O-Lab, Islamabad, Prof. Pervez Hoodbhoy, a retired theoretical physicist, QAU, Islamabad, LUMS, Lahore, and MIT, USA, Prof. Mark Breese, Ms. Ren Minqin, Ms. Debbie Seng, Dr. A. A. Bettiol, Dr. Markus Zmeck, National University of Singapore, Dr. KarlHeinz Schmidt, GSI, Germany, Dr. Dietrich Hermsdorf, Dresden, Germany, Prof. Tony Peaker, University of Manchester, UK, and Miss Raaz, The National Institute of the Rehabilitation, PIMS, Islamabad, are appreciated and gratefully acknowledged. I am thankful to Mr. Paul Murray from AREVA Federal Services LLC, 7207 IBM Drive, Charlotte, NC 28262, for his comments on the manuscript and grateful to Dr. Lin Shao, from Texas A \& M University, USA, for permission to adopt his plot as a figure in this manuscript. Many thanks to Prof. Faleh Abu-Jarad, Energy Research laboratory/Research Institute King Fahd University of Petroleum and Minerals Dhahran-31261, Saudi Arabia, Dr. Yajing Fu, Shanghai Institute of Applied Physics, Chinese Academy of Sciences, Shanghai 201800, China, Prof. Hideo Nakajima, The Institute of Scientific and Industrial Research, Osaka University, Ibaraki, Osaka, Japan, Prof. Harry J. Whitlow, Lund University and Institute of Technology, Lund, Sweden, and University of Jyväskylä, Finland, Dr. Walter Scandale, CERN, Switzerland, Prof. Walter Greiner, Frankfurt Institute for Advanced Studies, Johann Wolfgang Goethe-Universität, Frankfurt, Germany, Dr. Sandro Scandolo, AS-ICTP, Trieste, Italy, Dr. M. S. AlSalhi \& Dr. M. R. Baig, Dept. of Phys. \& Astron., King Saud University, Riyadh, Saudi Arabia, for useful exchange of views. I appreciate the inspirations from Okara \& Swiss Cheese, Hamd/Naat khawan/show mediators/singers/actors, Qari Khushi Mu-hammad, Umm-e-Habibah, Qari Waheed Zafar Qasmi, Naheed Akheter, Hadiqa Kiani, Anwar Maqsood, Moeen Akhter, Bushra Ansari, Allan Fakir, Muhammad Ali Shahki, Khayal Muhammad, Musarrat Shaheen, Ghazanfer Ali, Pathaney Khan, Jamal Shah, Mah Noor Balauch, Faryal Gohar, Tahir Naeem, Sher Khan Auditorium, Shankyari Cantt. I dedicate this article to Ms. Zubaida Jalal, an educationist from Kech, Balochistan for her efforts to raise literacy in Pakistani women, Urdu poets Amjad Islam Amjad \& Iftikhaar Arif due to their heartfelt poetry, Charles Dickenson, the author of the serial novel the "Great Expectations," my teachers Mr. Ahmed Tallat Fatami, Pakistan Land-AirWater Nuclear Safety Methodologies' Initiative (PAKLAW-NSMI), PAEC, Islamabad, Prof. Frank Watt, National University of Singapore, and Dr. S. Bashir, Dr. Fawaad \& Mr. Faizan-ul-Haq (CASP, GCU, Lahore), and Singers/Actors Noor Jahan, Nabeel Bulbula, Arif Lohar, Salman Khan \& Shakira. "Mr. Syed Qamar Hasnain, KANNUP/KINPOE, Karachi, Ms. Sabiha Bakhtiyar, INNUP, Islamabad, Dr. Sabiha Mansoor Sahiba, LCWL. Professional efforts by the personals from the National Nuclear Security System (NSS) which includes selections from PAEC, KRL, NESCOM, SUPARCO, PNRA, SPD, Pakistan Burri Fauj, Pakistan Fizaea, Pakistan Navy and Pakistan Services agencies are heartedly realized/appreciated. Very special thanks to the Security Guards and the Cleaning Examination Staff of NSS for help in organizing a small experiment on the safety check of a security container/box. Support from UN/IAEA in the provision of the Literature and related matters are acknowledged. Continued support from my parents (Mr. Master Saeed Ahmed \& Ms. Sughra), Parents in Law (Mr. Subaidar Nazir Ahmed \& Ms. Khaleida), my wife Ms. Shamila \& her close friend Naurina and Dr. Maqbool Ahmed Bhatti is also heartly appreciated. Discussion with friends Mr. M. Akhtar (DCS) \& S. Usman, Mr. Safdar Kayani and Mr. Tariq Azeem (IAD) are thankfully acknowledged. Inspiration from poets $\mathrm{Mu}$ hammd Iqbal (Sialkot) \& Faiz Ahmad Faiz (Narowal), John Nash, US, Pakistani Nobel Laureate A. Salam, an Egyptian born Nobel laureate Ahmed Hassan Zewail, the founder of Pakistan M.A. Jinnah, Anwar (NILOPE) \& Dr. Hafiz Faisal (ICCC), Ms. Fariha Malik, Azaan N. Khan and a close friend Mr. Abdullah (Faisalabad) is recognized. Struggle/dedication by Mr. Ghulaam Ali, Nelson Mandela, boxer Muhammad Ali, Michael Jackson, Maddona, Singers Bismillah \& Kaley Khan, my school teachers Munir \& Afzal (Zafarwali), Pir Mehar Ali Shah, Mr. Abdul Karim, Mr. Riaz Librarian, Javed Bashir (JB), Ms. Eva (NUS). Dr. Mariyam Giorgini, Badar Mian Qawaal, actor Omar Sharif, actresses Meera, Rani \& Rekha 
(Ida by Mirza Ruswa), and Sir Ganga Rama is appreciated. Help of the WJNST Editorial Board \& Staff Members for waving off the publication fee and the help in the improvement of figures and composing of the manuscript is very thankfully acknowledged. Possible discovery of Higgs Boson (HB) and/or HG like particle at CERN is a source of strength for long standing motivations in science." Useful interactions with several young/enthusiastic and ever-cooperative colleagues, friends Aziz, Tanwir, Tabarak, Nisar, Ayaz, Mumtaz, Allah Ditta, Islam, Aurangzeb, Fozia Imran, Najamul-Haq, Asma Latif, Zahid Munir, Atif Raza, Naveed, Dr. I. H. Bukhari, Asif Bashir, Rafia Mir, Shazia Saeed, Ms. Wasim Yawar, Miss Ishrat Rehan, Miss Rehana Mukhtar, Shahid Mukhtar, Tariq J. Sulaija, Farhat Waqar, Dr. Shahid Bilal, Syeda Jan, Mr. Shahid Riaz, Tayyab Mehmood, Tariq Mahmood, Atta Muhammad, Waqar Murtaza, Mansoor Sheikh, Ms. Shahida Waheed, Nasir Khalid, Dr. Sohaila Rahman, M. Arshad, Habib-ur-Rahman, Muhammad Siddiq, Syeda Sahar Rizvi, Athar Saeed, Yasir Faiz, Saadia Zafar Bajwa, Sumaira Naz, Hassan Waqas, Mudassir, Asif Shah, Zafar Yasin, Qamar-ul-Haq, Saira Butt, Nadeem Yaqoob, Ayesha Yameen, Jawaria Abid, Sajjad Mirza, Sh. Hussain, S. Hussain, Dr. N. Ali, Dr. M. I. Shahzad, Dr. N. U. Khattak. Eng. M. Fayyaz, Masood Anwar, Gul Sher, Dr. Samina Roohi, Rizwana Zahoor, Saima Tariq, Jamil Tariq, Dr. Khalid Saleem, Dr. Tabinda, Dr. Samina Gul, Farina Kanwal, Irum Mehboob Raja, Farid Khan, Kabul Shah, Saad Maqbool Bhatti, Dr. Shafqat Farooq, Badar Suleman, Dr. Khalid Jamil, Dr. Mansha Ch., Ansar Pervez, Mirza Brothers, Arshad Zia, Bakhtiar Majid, Arshad Zia, Munir Ahmad, Shahid Munir, Waseem Hassan, Imtiaz Rabbani, Imtiaz Abbasi, Athar Farooq, Sajjad Malik, Javaid Irfan, Abdul hameed, M. Javed, Anwar-ul-Islam, Jamshed Cheema, Abdul Hai, Mr. Zaka-ud-Din, Syed Arif Ahmad, Sher Jan, Iqbal Ali Azhar, S. H. Jaffri, Anwar Habib, M. Iqbal, Zaheer Baig, M. Ali, Shahid Mallick, Abdul Mannan, Gulam Nabi, Zia-ul-Hassan, Adnaan Kaiyani, M. M. Ashfaq, Khurshid Alam, M. Majid Azim, Khalid Mahmood, Imran Zaka, A. A. Niazi, Faiq Hanif, Jahangir Haider, Muhammad Naeem, Tariq Saleemi, Zahid Rana, Muhammad Sajid, Eng. Hashim, Qaisar Abbas, Qamar Abbas, Waqas Masood, Zulfiqar Ali, Shaukat Ali, Abbas Ali, Maj. Shabbir Sharif, Lance Naik Muhammad Mahfooz, Pilot Rashid Minhaas, Maj. Tufail Muhammad, Maj. Azeez Bhatti, Sarwar Muhammad Hussain, Capt. Muhammad Sarwar, Maj. Muhammad Akram, Hawaldar alak Jan, Capt. Karnal Sher Khan, Naik Saif Ali Janjua, Naveed Ikram Bhatti, Muhammad Kashiff, Dr. Shafkat Karim, Amjad Nisar, Library, Muhammad Farooq, Nasrullah Khan Qazi, H. A. Khan, N. Ahmad, M. Jahangir, J. I. Akhter, Eng. Nisar Ahmed, Nazar Hussain, A. H. Qureshi, Ms. Sabahat Nasir Ahmad (HP D), Dr. Nasir Ahmad, Luqman Ahmad (NCD), SGs:
Muhammad Zahoor, Basharat Hussain, Muhammad Akram; Muhammad Saeed (Zafarwal), Manzoor Hussain (Narowal), Sohail Ahmad (Baddo Malhi), Ms. Sabira Manzoor, Mukkarram Shah, Shahid Mahmood, Kaleem Haider, Tanvir Akhter, Malik Muhammad Zubair, Sartaj Ali.

Anticipation by several people around the world and in my home country contributed to shaping up my thoughts/ knowledge and even life in multi-disciplinary manners (in direct contact, indirect contact and contact less, and regular, temporary and permanent exposures of/to the world). Some of them include King Abdullah, Yasir Arafat, Sheikh Abdullah bin Zayed Al Nahyan, Queen Elizabeth, Recep Tayyip Erdoğan, Mao Zedong, Mahateer Muhammd, Lee Kuen Yew, Zakir Naik, Mother Treesa, Qari Abdul Basit, Umm-e-Habiba, Muniba Sheikh, John F. Kennedy, Michael Jackson, Jennifer Hudson/ Jennifer Lopez, Imran Khan, Jahangir Khan, Jan Sher Khan, Shahbaaz (senior \& junior), Paul O'Connell, Diego Maradona, Recep Tayyip Erdoğan, Fareed Zakaria, Zubaida Khanum, Aesam-ul-Haq. I was benefited by several people at the The Punjab University (PU): Dr. Naseem Shahzad, Dr. Khadim Hussain, Ali Haider, PIEAS, Zafar Iqbal the Quaid-e-Azam University (QAU), the Govt. College University (GCU): Ms. Farzana Ashraf, M. Arshad, Ch. Arshad, Zohra Nazir, Malik A. Ghafoor, Kashiff Ahmad, Mr. Zafar Iqbal, Muhammad Humayun; Dr. Shoaib Ahmad, Church Road CASP (GCU), Dr. Zafar Iqbal, CIIT, Prof. Asghar Qadir, NUST, Col. Tanvir, Zahid, Arshad, Talib JLA, Shankyari, Tajdar Adil (LUMS); National University of Singapore: Prof. S. J. Chua (IMRE), several people at Dar-us-Salaam, Singapore, Dr. Chammika Udalagamma, Mr. Ang Kwak Te, Ms. Yvonne Seah, Prof. Thomas Osipowicz, Ms. Reshmi Rajendern, Mangi, Ms. Hasma Hamza, OSA, Gillman Heights \& PGP Residences, Singapore, Prof. Ping Yuen Feng, Dr. Leszek Lewinsky, Dr. J. van Kan, Ms Zhang Fang, Dr. Huang Long; the University of Manchester (UMIST): Prof. A. R. Peaker, Dr. Huda El mubarek, Dr. Frank Podd, Dr. Leszek Majewski and several other people of several disciplines, Mathematics, Chemistry and the UM Central Library (Oxford Road); Manchester Museum, the Royal Northern College of Music, Oxford Road, Manchester. Radiation Damage Workshop (2010), the ASICTP, Trieste Italy; John Elis et al. \& UA9 collaboration, the CERN, Switzerland; Nuclear Security Summit, Seoul 2012 participants; Prof. L. J. Van Ijzendoorn, Eindhoven University of Technology, The Netherlands, Minaal \& Saim, the National University of Ireland (NUI), Prof. W. Ensinger, Institute of Material and Earth Science, Darmstadt University of Technology, Darmstadt, Germany; Alexander M. Taratin, Joint Institute for Nuclear Research, Joliot-Curie 6, 141,980, Dubna, Moscow Region, Russia, Los Almos National Laboratory (LANL): Jorgen 
Randrup, Peter Moller; Stepan G. Mashnik; University of Colorodo (UC): Jerry Peterson, University of Aarhu, Denmark (UAD): Prof. Soeren Pape Moeller, Prof. J. U. Andersen; Prof, Hans Henrik Andersen, the Niels Bohr Institute of the University of Copenhagen, Denmark. The acknowledgements are partly to revisit myself in gathering thoughts/knowledge acquired at several stages of my life.

\section{REFERENCES}

[1] L. K. Hamdan, J. C. Walton and A. Woocay, "Safety Implication for an Unsaturated Zone Nuclear Waste Repository," Energy Policy, Vol. 38, No. 10, 2010, pp. 57335738. doi:10.1016/j.enpol.2010.05.022

[2] D. F. Rucker, M. T. Levitt and W. J. Greenwood, "ThreeDimensional Electrical Resistivity Model of a Nuclear Waste Disposal Site," Journal of Applied Geophysics, Vol. 69, No. 3-4, 2009, pp. 150-164. doi:10.1016/j.jappgeo.2009.09.001

[3] M. B. Schaffer, "Toward a Viable Nuclear Waste Disposal Program," Energy Policy, Vol. 39, No. 3, 2011, pp. 1382-1388.

[4] D. Butler, "Nuclear Power's New Dawn," Nature, Vol. 429, No. 6989, 2004, pp. 238-240. doi:10.1038/429238a

[5] L. Devell, H. Tovedal, U. Bergström, A. Appelgren, J. Chyssler and L. Andersson, "Initial Observations of Fallout from the Reactor Accident at Chernobyl," Nature, Vol. 321, No. 6067, 1986, pp. 192-193. doi:10.1038/321192a0

[6] D. Williams and K. Baverstock, "Chernobyl and the Future: Too Soon for a Final Diagnosis," Nature, Vol. 440, No. 7087, 2006, pp. 993-994. doi:10.1038/440993a

[7] M. Peplow, "Counting the Dead," Nature, Vol. 440, No. 7087, 2006, pp. 982-983. doi:10.1038/440982a

[8] J. J. Bevelacqua, "Applicability of Health Physics Lessons Learned from the Three Mile Island Unit 2 Accident to the Fukushima Daiichi Accident," Journal of Environmental Radioactivity, Vol. 105, No. 1, 2012, pp. 6-10. doi:10.1016/i.jenvrad.2011.10.008

[9] G. Brumfiel, "Chernobyl and the Future: Forward Planning," Nature, Vol. 440, No. 7087, 2006, pp. 987-989. doi: $10.1038 / 440987 \mathrm{a}$

[10] G. A. Cowan, "Scientific Applications of Nuclear Explosions," Science, Vol. 133, No. 3466, 1961, pp. 1739-1744. doi:10.1126/science.133.3466.1739

[11] C. Macilwain, "Out of Sight, Out of Mind?" Nature, Vol. 412, No. 6850, 2001, pp. 850-852. doi:10.1038/35091156

[12] J. Mazeika, R. Petrosius, V. Jakimaviciute-Maseliene, D. Baltrunas, K. Mazeika, V. Remeikis and T. Sullivan, "Long-Term Safety Assessment of a (Near-Surface) ShortLived Radioactive Waste Repository in Lithuania," $\mathrm{Nu}$ clear Technology, Vol. 161, No. 2, 2008, pp. 156-168.

[13] J. E. Cantlon, "Nuclear Waste Management in the US: The Nuclear Waste Technical Review Board's Perspective," Nuclear Engineering and Design, Vol. 176, No. 1-2, 1997, pp. 111-120. doi:10.1016/S0029-5493(96)01339-8
[14] F. Decamps and L. Dujacquier, "Overview of European Practices and Facilities for Waste Management and Disposal," Nuclear Engineering and Design, Vol. 176, No. 1-2, 1997, pp. 1-7. doi:10.1016/S0029-5493(96)01335-0

[15] Y. Maki and H. Ohnuma, "Application of Concrete to the Treatment and Disposal of Radioactive Waste in Japan," Nuclear Engineering and Design, Vol. 138, No. 2, 1992, pp. 179-188. doi:10.1016/0029-5493(92)90294-6

[16] P. Poskas, R. Kilda, V. Ragaisis and T. M. Sullivan, "Impact of Spatial Heterogeneity of Source Term in NearSurface Repository on Releases to Groundwater Pathway," Nuclear Technology, Vol. 161, No. 2, 2008, pp. 140-155.

[17] M. A. Rana, "A New Method for Monitoring the Radiation Damage in Nuclear Waste Containers Using Ion Channeling," Annals of Nuclear Energy, Vol. 35, No. 8, 2008, pp. 1580-1583. doi:10.1016/j.anucene.2008.01.015

[18] A. Verbruggen, "Renewable and Nuclear Power: A Common Future?" Energy Policy, Vol. 36, No. 11, 2008, pp. 4036-4047. doi:10.1016/j.enpol.2008.06.024

[19] J. Giles, "Chernobyl and the Future: When the Price is Right," Nature, Vol. 440, No. 7087, 2006, pp. 984-986. doi:10.1038/440984a

[20] M. Wahlen, C. O. Kunz and J. M. Matuszek, "Radioactive Plume from the Three Mile Island Accident: Xenon133 in Air at a Distance of 375 Kilometers," Science, Vol. 207, No. 4431, 1980, pp. 639-640. doi:10.1126/science.7352276

[21] W. C. Sailor, D. Bodansky, C. Braun, S. Fetter and B. van der Zwaan, "A Nuclear Solution to Climate Change?" Science, Vol. 288, No. 5469, 2000, pp. 1177-1178. doi:10.1126/science.288.5469.1177

[22] R. L. Cowan et al., "The ABWR General Plant Description, GE Nuclear Energy," Nuclear Energy, San Jose, 1999.

[23] I. Farnan, H. Cho and W. J. Weber, "Quantification of Actinide $\alpha$-Radiation Damage in Minerals and Ceramics," Nature, Vol. 445, No. 7124, 2007, pp. 190-193. doi: $10.1038 /$ nature 05425

[24] J. Delay, H. Rebours, A. Vinsot and P. Robin, "Scientific Investigation in Deep Wells for Nuclear Waste Disposal Studies at the Meuse/Haute Marne Underground Research Laboratory, Northeastern France," Physics and Chemistry of the Earth, Vol. 32, No. 1-7, 2007, pp. 42-57.

[25] R. C. Ewing, "The Nuclear Fuel Cycle: A Role for Mineralogy and Geochemistry," Elements, Vol. 2, No. 6, 2006, pp. 331-334. doi:10.2113/gselements.2.6.331

[26] E. C. Buck, B. D. Hanson, B. K. McNamara, R. Gieré and P. Stille, "Energy, Waste and the Environment: A Geochemical Perspective," Geological Society of London, Vol. 236, 2004, pp. 65-68.

[27] C. Poinssot, C. Ferry, P. Lovera, J. C. Christophe and J.-M. Gras, "Spent Fuel Radionuclide Source Term Model for Assessing Spent Fuel Performance in Geological Disposal. Part II: Matrix Alteration Model and Global Performance," Journal of Nuclear Materials, Vol. 346, No. 1, 2005, pp. 66-77. doi:10.1016/j.jnucmat.2005.04.071 
[28] D. R. Wiles, "The Chemistry of Nuclear Fuel Waste Disposal," Polytechnique International Press, Montréal, 2006.

[29] M. Bun, S. Fetter, J. P. Holdren and B. van der Zwaan, "The Economics of Reprocessing Versus Direct Disposal of Spent Nuclear Fuel," Report DE-FG26-99FT4028, Harvard University, Cambridge, 2003.

[30] M. A. Rana, "A Compound Spike Model for Formation of Nuclear Tracks in Solids," Nuclear Science Techniques, Vol. 18, No. 6, 2007, pp. 349-353. doi:10.1016/S1001-8042(08)60006-8

[31] L. C. Feldman, J. W. Mayer and S. T. Picraux, "Materials Analysis by Ion Channeling: Submicron Crystallography," Academic Press, New York, 1982.

[32] I. Farnan, H. Cho and W. J. Weber, "Identifying and Quantifying Actinide Radiation Damage in Ceramics with Radiological Magic-Angle Spinning Nuclear Magnetic Resonance," MRS Symposium Proceedings, Vol. 986, No. 1, 2007, pp. 197-206.

[33] L. Shao, "Toward High Accuracy in Channeling Rutherford Backscattering Spectrometry Analysis," Nuclear Instruments and Methods in Physics Research Section B: Beam Interactions with Materials and Atoms, Vol. 266, No. 6, 2008, pp. 961-964. doi:10.1016/j.nimb.2008.02.008

[34] S. Goto, H. Kobayashi, Y. A. Hideo, T. Kimura and H. Hayashi, "Corrosion-Resistant Copper Alloy," US Patent No. 4830825, 1989.
[35] M. O. Schwartz, "High Level Waste Disposal, Ethics and Thermodynamics," Environmental Geology, Vol. 54, No. 7, 2008, pp. 1485-1488. doi:10.1007/s00254-007-0929-x

[36] D. H. Oughton, "Ethical Values in Radiological Protection," Radiation Protection Dosimetry, Vol. 68, No. 3-4, 1996, pp. 203-208.

doi:10.1093/oxfordjournals.rpd.a031865

[37] F. Birol, "Nuclear Power: How Competitive down the Line?" IAEA Bulletin, Vol. 48, No. 2, 2007, pp. 16-20.

[38] J. I. Dawson and R. G. Darst, "Meeting the Challenge of Permanent Nuclear Waste Disposal in an Expanding Europe: Transparency, Trust and Democracy," Environmental Politics, Vol. 15, No. 4, 2006, pp. 610-627. doi:10.1080/09644010600785226

[39] A. MacFarlane, "Stuck on a Solution," Bulletin of Atomic Scientists, Vol. 62, No. 3, 2006, pp. 46-52. doi: $10.2968 / 062003012$

[40] C. Thegerström, "Down to Earth and Below: Sweden's Plans for Nuclear Waste," IAEA Bulletin, Vol. 46, No. 1, 2004, pp. 36-38.

[41] E. Watanabe, B. Lake and M. Kuraishi, "Association for Aid and Relief," Tokyo. http://www.globalgiving.org/japan-updates

[42] D. Cyranoski, "After the Deluge: Japan Is Rebuilding Its Coastal Cities," Nature, Vol. 483, No. 7388, 2012, pp. 141143. doi:10.1038/483141a 